\title{
Polymorphisms of angiotensin-converting enzyme (ACE) and ACE2 are not associated with orthostatic blood pressure dysregulation in hypertensive patients
}

\author{
Xiao-han FAN ${ }^{1}$, Yi-bo WANG ${ }^{2}$, Hu WANG ${ }^{2}$, Kai SUN ${ }^{2}$, Wei-li ZHANG ${ }^{2}$, Xiao-dong SONG ${ }^{2}$, Jing-zhou $\mathrm{CHENG}^{2}$, Hai-ying WU ${ }^{1}$, \\ Xiang-liang $\mathrm{ZHOU}^{1}$, Ru-tai $\mathrm{HUI}^{1, *}$ \\ ${ }^{1}$ Department of Cardiology and Hypertension Division, ${ }^{2}$ Sino-German Laboratory for Molecular Medicine \& Key Laboratory for Clinical \\ Cardiovascular Genetics, Ministry of Education, Cardiovascular Institute \& FuWai Hospital, Chinese Academy of Medical Sciences and \\ Peking Union Medical College, Beijing 100037, China
}

\begin{abstract}
Aim: The genetic background of orthostatic blood pressure dysregulation remains poorly understood. Since the renin-angiotensin system plays an important role in blood pressure regulation and response to position change, we hypothesized that angiotensin-converting enzyme $(A C E)$ and ACE2 genetic polymorphisms might contribute, at least partially, to orthostatic blood pressure dysregulation in hypertensive patients.

Methods: Two tag single nucleotide polymorphisms (SNPs) of ACE2 and ACE I/D were genotyped in 3630 untreated hypertensive patients and 826 normotensive subjects. Orthostatic hypertension was defined as an increase in systolic blood pressure of $20 \mathrm{mmHg}$ or more and orthostatic hypotension as a drop in blood pressure of $20 / 10 \mathrm{mmHg}$ or more within three minutes of assumption of upright posture.

Results: Female and male patients had similar rates of orthostatic hypertension (16.5\% vs 15.3\%) and hypotension (22.5\% vs $23.8 \%$ ). No significant differences were detected in the minor allele frequency of ACE2 rs2106809, rs2285666, or ACE I/D in either female or male patients with orthostatic hypertension (15.1\%, 22.7\%, 19.6\%, respectively), hypotension (13.8\%, 25\%, 16.5\%), or normal orthostatic blood pressure response $(14.4 \%, 21.9 \%, 15.8 \%)$ in additive, dominant or recessive models after adjustment for confounders (all $P>0.05$ ). The orthostatic changes in systolic and diastolic blood pressure were also comparable among patients carrying different genotypes. Similar results were observed in normotensive subjects.

Conclusion: These data provide no support for the involvement of ACE or ACE2 in the genetic predisposition to orthostatic hypotension or hypertension.
\end{abstract}

Keywords: orthostatic hypotension; hypertension; angiotensin-converting enzyme; polymorphism

Acta Pharmacologica Sinica (2009) 30: 1237-1244; doi: 10.1038/aps.2009.110; published online 17 August 2009

\section{Introduction}

Orthostatic hypotension $(\mathrm{OH})$ is well recognized as a risk factor for falls, syncope, cardiovascular events and mortality ${ }^{[1-5]}$. Orthostatic hypertension (OHT), a rise in blood pressure (BP) upon assuming upright posture, has been associated with increased risk of coronary heart disease ${ }^{[6]}$, silent cerebrovascular infarct ${ }^{[7]}$, and lesions in the central nervous system detected by $\mathrm{MRI}^{[8]}$. Hypertension has been associated with increased risk of $\mathrm{OH}$ and $\mathrm{OHT}$ in addition to multiple other

\footnotetext{
* To whom correspondence should be addressed.

E-mail huirutai@sglab.org

Received 2009-03-08 Accepted 2009-06-19
}

factors, including older age, diabetes mellitus, decreases in vestibular function, and medication in many epidemiological studies $^{[2,3,9-11]}$. Therefore, a better understanding of the underlying pathophysiology and genetic background might have major clinical significance for hypertensive patients.

The actual mechanisms of orthostatic BP dysregulation are poorly understood. When a person stands, about 500-1000 $\mathrm{mL}$ of blood moves from the upper body to the lower body. In response to postural changes, the sympathetic nervous system, the renin-angiotensin system (RAS), and consequent aldosterone release may be activated and exert compensatory effects for maintaining cardiac output during the stress of upright posture $^{[12]}$. Apart from the key role of the autonomic nervous 
system in the short- and long-term BP response to postural changes, RAS is also believed to be an important regulator of orthostatic BP change. Because RAS hyperactivity is involved in the pathogenesis of hypertension, the effect of RAS on orthostatic BP regulation needs to be evaluated in hypertensive patients. The inter-individual response to postural change is highly variable ${ }^{[6]}$, and familial analyses have revealed that $25 \%$ of the variance of change in systolic blood pressure (SBP) is attributable to genetic factors ${ }^{[13]}$. Previous studies have suggested that genetic variants contribute to the presence of $\mathrm{OH}$ and OHT. Genetic norepinephrine transporter dysfunction is associated with orthostatic intolerance and changes in norepinephrine turnover ${ }^{[14]}$. Some mitochondrial DNA mutations are also associated with idiopathic $\mathrm{OH}^{[15]}$. Thus, genes encoding components of the RAS may also be good candidate genes for orthostatic BP dysregulation in hypertensive patients because of their involvement in both the pathogenesis of hypertension and orthostatic BP regulation.

A newly discovered RAS component, angiotensin-converting enzyme 2 (ACE2), shares $42 \%$ identity with the catalytic domain of somatic ACE and has been reported to play a protective role in the regulation of $\mathrm{BP}$ homeostasis and cardiac function $^{[16-18]}$. ACE and ACE2 may therefore coordinate the physiological functions of RAS, and the balance between ACE2 and ACE may play an important role in the pathophysiology and development of disease. Given previous finding ${ }^{[19]}$ of no associations between $\mathrm{OH}$ and polymorphisms of genes encoding traditional RAS components [including ACE I/D, angiotensinogen (AGT) M235T and angiotensin II type 1 receptor (AT1R) A1166C], we preferred ACE2 and ACE as candidate susceptibility genes for orthostatic $\mathrm{BP}$ dysregulation. To test our hypothesis, we looked for associations between ACE and $A C E 2$ polymorphisms and $\mathrm{OHT}$ and $\mathrm{OH}$ in 3630 untreated hypertensive patients and 826 normal BP subjects.

\section{Methods}

\section{Study Population}

A community-based cross-sectional study was conducted in XinYang County, a region in central China, from 2004 to 2005. Hypertension was defined as diastolic blood pressure (DBP) of $\geq 90 \mathrm{mmHg}$ and/or SBP of $\geq 140 \mathrm{mmHg}$ or currently taking medication for hypertension (as defined by WHO 1999). Subjects were excluded from the study if they had any known diseases, including heart failure, renal failure, valvular heart disease, secondary hypertension, and severe debilitating chronic illness (cancer, renal or hepatic diseases). To exclude the effect of antihypertensive drugs on orthostatic BP regulation, only untreated patients were included in the study. Untreated patients were defined as those newly diagnosed with hypertension and/or not receiving any antihypertensive drugs for at least 8 weeks, according to participants' self-reports on medication history. Concurrently, age- and sex-matched subjects with systolic and/or diastolic BP levels $<130 / 85 \mathrm{mmHg}$ and with no family history of hypertension were recruited as normotensive subjects from the same communities. In total, 3630 untreated patients (1227 men and 2403 women) and 826 nor- motensive subjects (286 men and 540 women) with valid data on orthostatic BP measurements were included in the study. This study was reviewed and approved by the ethical committees of FuWai and local hospitals, and informed consent was obtained from each subject before he or she was recruited.

\section{Data collection}

Each eligible participant was interviewed in a community clinic. Anthropometric measurements, including height (m), weight $(\mathrm{kg})$, waist and hip circumference (measured at the umbilicus and the widest point, respectively), were measured by trained researchers. All subjects underwent a standard 12-lead ECG. Overnight fasting blood was drawn for assays of fasting blood glucose, blood lipids [total cholesterol (TC), triglycerides (TG), high-density lipoprotein cholesterol ( HDL-C), low-density lipoprotein cholesterol ( LDL-C )], serum uric acid and creatinine levels by the core laboratory at FuWai Hospital. Medical history and histories of cigarette smoking and alcohol consumption were obtained with a standardized questionnaire. Obesity was defined as BMI $\geq 30.0$ according to World Health Organization criteria. Metabolic syndrome (MS) was determined according to the International Diabetes Federation (IDF) criteria of 2005.

\section{Blood pressure measurement and classification of orthostatic blood pressure change}

Sitting BP was measured by trained nurses and physicians with a standardized mercury sphygmomanometer and appropriate cuff sizes (regular, large, or thigh) fitted to the subject's right arm. Three readings were recorded in a sitting position at least $30 \mathrm{~s}$ apart after more than 5 minutes of rest, and the average of the three readings was taken as the analyzed BP level. All BP investigators had to complete a training program on the preparation of study subjects for measuring $\mathrm{BP}$, selection of correct cuff size, and standard BP measurement technique according to a common protocol adapted from procedures recommended by the American Heart Association ${ }^{[20]}$.

Supine and standing BP were recorded with a mercury sphygmomanometer following a standardized protocol by a trained physician or nurse. After a 15-min ECG examination with the participant lying on an examination table, three supine measurements of $\mathrm{BP}$ and heart rate were recorded at approximately 30 -s intervals by a trained professional. Participants were then asked to rise from the supine position with the entire forearm relaxed and supported at heart level on an adjustable table, and standing measurements were taken at 0 and $2 \mathrm{~min}$. $\mathrm{OH}$ was defined as a decline in SBP of at least 20 $\mathrm{mmHg}$ and/or a decline in DBP of at least $10 \mathrm{mmHg}$ either 0 or $2 \mathrm{~min}$ after shifting from a supine to an upright posture ${ }^{[21]}$. The definition of OHT was a postural increase of at least 20 $\mathrm{mmHg}$ in the orthostatic SBP ${ }^{[22]}$. The orthostatic BP change was calculated as the average of two standing BP readings minus the average of the supine BP readings. Participants with neither of these two patterns were classified into the orthostatic normotension (ONT) group. 


\section{Polymorphism selection and genotyping}

Five previously selected tagging single nuclear polymorphisms (SNPs) (rs4646112, rs2285666, rs2106809, rs4646155, and rs879922) reflect most of the information across the 60 $\mathrm{kb}$ around the ACE2 gene according to the HapMap Project CHB (Han Chinese in Beijing) database (public releases up to January 2006) and the NCBI database; details have been previously published $^{[23]}$. In brief, because the SNP rs4646112 is not polymorphic, and SNPs rs4646155 and rs879922 occur at relatively low minor allele frequency (at 3\% 5\%) among the Chinese, we selected the remaining two tag SNPs (rs2106809, and rs2285666), which effectively capture most of the other unmeasured common SNPs with allele frequencies $>5 \%$. ACE2 rs2106809 was found to be in pairwise LD $\left(r^{2}=0.742\right.$, $\mathrm{D}^{\prime}=1.0$ ) with three SNPs (rs2097723, rs1548474, rs1356037) in the region upstream of the ACE2 gene, while SNP rs2285666 was in strong LD with two SNPs (rs1978124, rs4646142) $\left(r^{2}=0.929 \sim 0.995, \mathrm{D}^{\prime}=0.854 \sim 0.973\right)$ in Chinese. These two polymorphisms of ACE2 were genotyped in all studied subjects by standard polymerase chain reaction (PCR)-restriction fragment length polymorphism (RFLP) techniques. All aspects of DNA source, preparation and genotyping were controlled using the paradigms of blindness and randomization. We also selected ACE I/D polymorphism, which accounts for up to $50 \%$ of the variation in the circulating level of $\mathrm{ACE}^{[24]}$. To determine $A C E$ I/D polymorphism, insertion sequence-specific PCR was also performed to avoid mistyping ${ }^{[25]}$. The reproducibility of the genotyping was confirmed by bidirectional sequencing in 100 randomly selected samples, and the reproducibility was $100 \%$.

\section{Statistical analysis}

All data are expressed as means with 95\% confidence intervals. Because the ACE2 gene is located on the $\mathrm{X}$ chromosome, all of the data for each sex were analyzed separately (SPSS13.0). Quantitative variables were compared with one-way analysis of variance (ANOVA), and Tukey's test or the t-test was used for comparison of the mean values of pairs of groups. Triglyceride level was highly skewed and compared using a MannWhitney nonparametric test. A $\chi^{2}$ test was used for qualitative variables, genotype/allele frequencies, and for the HardyWeinberg equilibrium of polymorphisms. Haplotypes were inferred using PHASE 2.0, and then were compared by $x^{2}$ test. Multinomial logistic regression analysis was used to assess the contribution of all genotypes to $\mathrm{OHT}$ or $\mathrm{OH}$ with adjustments for age, BMI, sitting BP levels, heart rates, and other conventional confounders. The orthostatic BP changes among genotypes were first analyzed by ANOVA or $t$ test, and then by a general linear model with adjustment for age, BMI, and sitting BP levels. A two-tailed $P$ value of $<0.05$ was considered significant. Assuming an additive model, the study had more than $80 \%$ statistical power to detect an association (at $P=0.05$ ) with an odds ratio of $1.25-1.75$ for alleles at $35 \%-45 \%$ frequency, which indicates a low probability of a false-negative result.

\section{Results}

Clinical characteristics, prevalence of $\mathrm{OHT}$ and $\mathrm{OH}$, and orthostatic BP changes by sex

Table 1 summarizes the baseline characteristics and the prevalence of $\mathrm{OHT}$ and $\mathrm{OH}$ in hypertensive patients and normotensive subjects by sex. In general, most characteristics were significantly different between the sexes except for age and diabetes mellitus. The prevalence of neither OHT nor OH differed between men and women, even after adjustment for risk factors in both hypertensive and normotensive subjects. Male and female subjects had similar orthostatic reductions in SBP at both 0 and 2 min after standing (Table 1) and similar orthostatic increases in DBP at 0 min after rising from a supine to an upright posture. However, in hypertensive patients, men had higher orthostatic increases in DBP at 2 min after standing than did women even after adjustment for confounders, as determined by analysis of a general linear model $(3.3 \mathrm{mmHg}$ vs $2.6 \mathrm{mmHg}, P=0.046)$.

\section{Associations of $\mathrm{OH}$ and $\mathrm{OHT}$ with genotypes in hypertensive and normotensive subjects}

The genotype/allele frequencies of the two SNPs corresponding to ACE2 and ACE I/D in untreated hypertensive patients and normotensive subjects are listed in Tables 2 and 3. Hardy-Weinberg equilibrium for the two ACE2SNPs could be tested only in the female population, and it showed no significant deviation in either hypertensive (rs2106809: $\chi^{2}=3.49$, $P=0.061$; rs2285666: $\left.\chi^{2}=3.46, P=0.062\right)$ or normotensive women (rs2106809: $\chi^{2}=2.88, P=0.09$; rs2285666: $\left.\chi^{2}=0.14, P=0.71\right) . \quad A C E$ $\mathrm{I} / \mathrm{D}$ genotypes were also in Hardy-Weinberg equilibrium in the entire hypertensive study population $\left(X^{2}=3.09, P=0.08\right)$ and in the normotensive subjects $\left(X^{2}=0.47, P=0.49\right)$. The distribution of each genotype was consistent with other published data on Chinese subjects.

Table 2 presents genotype and allele frequencies for each polymorphism in hypertensive women and men with OHT, $\mathrm{OH}$ and ONT. Analysis of single SNPs showed no significant differences in the minor allele frequency (MAF) of ACE2 rs2106809, rs2285666, or ACE I/D among female patients with OHT $(15.1 \%, 22.7 \%, 19.6 \%$, respectively), OH $(13.8 \%$, $25 \%, 16.5 \%$, respectively) and ONT (14.4\%, 21.9\%, 15.8\%, respectively), in dominant, recessive and additive models (all $P>0.05)$; nor were there differences among the male patients. The haplotypes inferred from the two ACE2 SNPs also showed no associations with $\mathrm{OH}$ or $\mathrm{OHT}$ in either sex. To adjust for covariates, subsequent multinomial logistic regression analysis was performed, and this too revealed no significant association between any of the tested SNPs and OH or OHT.

Similarly, as shown in Table 3, no association was observed between genotypes or haplotypes and $\mathrm{OHT}$ or $\mathrm{OH}$ in normotensive subjects, even after adjusting for conventional risk factors.

\section{Associations of orthostatic BP changes with genotypes}

The orthostatic BP changes in hypertensive patients were classified by genotype and sex (Table 4). However, no significant 
Table 1. Clinical characteristics and prevalence of $\mathrm{OH}$ and $\mathrm{OHT}$ by sexes.

\begin{tabular}{|c|c|c|c|c|}
\hline \multirow[t]{2}{*}{ Characteristics } & \multicolumn{2}{|c|}{ Untreated hypertensive patients } & \multicolumn{2}{|c|}{ Normotensive subjects } \\
\hline & Men & Women & Men & Women \\
\hline$n$ & 1227 & 2403 & 286 & 540 \\
\hline Age, year & $59.1(58.5-59.5)$ & $58.2(57.8-58.6)$ & $54.3(53.5-55.1)$ & 54.7 (53.9-55.5) \\
\hline $\mathrm{BMI}, \mathrm{kg} / \mathrm{m}^{2}$ & $25.4(25.3-25.7)$ & $26.3(26.1-26.4)^{\mathrm{b}}$ & $24.2(23.9-24.5)$ & $24.9(24.7-25.2)^{b}$ \\
\hline SBP, $\mathrm{mmHg}$ & $159.5(158.1-160.7)$ & $161.7(160.3-163.3)^{b}$ & $125.6(124.6-126.8)$ & $126.5(125.6-127.5)$ \\
\hline DBP, $\mathrm{mmHg}$ & $97.2(96.7-97.7)$ & $95.3(94.9-95.8)^{\mathrm{b}}$ & $82.9(82.1-83.9)$ & $81.7(81.0-82.4)^{\mathrm{b}}$ \\
\hline $\mathrm{PP}, \mathrm{mmHg}$ & $62.2(61.9-63.3)$ & $65.7(64.9-66.5)^{b}$ & $42.7(41.6-43.8)$ & $44.8(44.0-45.6)^{b}$ \\
\hline $\mathrm{HR}, \mathrm{bpm}$ & $71.6(70.9-72.3)$ & $73.8(73.4-74.3)^{\mathrm{b}}$ & $69.6(68.1-71.0)$ & $71.6(70.6-72.5)^{b}$ \\
\hline $\mathrm{FBG}, \mathrm{mmol} / \mathrm{L}$ & $5.56(5.50-5.68)$ & $5.60(5.52-5.67)$ & $5.21(5.09-5.31)$ & $5.36(5.22-5.50)$ \\
\hline SUA, $\mu \mathrm{mol} / \mathrm{L}$ & $345.3(340.2-350.1)$ & $262.9(260.1-265.7)^{b}$ & $324.7(315.6-333.7)$ & $242.2(236.5-248.0)^{b}$ \\
\hline $\mathrm{SCr}, \mu \mathrm{mol} / \mathrm{L}$ & $78.8(77.5-80.2)$ & $58.8(58.1-59.6)^{\mathrm{b}}$ & $74.3(72.6-76.0)$ & $56.6(55.6-57.7)^{\mathrm{b}}$ \\
\hline $\mathrm{TC}, \mathrm{mmol} / \mathrm{L}$ & $5.38(5.31-5.43)$ & $5.64(5.59-5.68)^{b}$ & $5.21(5.03-5.38)$ & $5.37(5.27-5.46)^{b}$ \\
\hline $\mathrm{HDL}-\mathrm{C}, \mathrm{mmol} / \mathrm{L}$ & $1.52(1.50-1.54)$ & $1.58(1.56-1.59)^{b}$ & $1.49(1.47-1.53)$ & $1.57(1.55-1.60)^{\mathrm{b}}$ \\
\hline LDL-C, mmol/L & $3.09(3.02-3.11)$ & $3.18(3.15-3.24)^{\mathrm{b}}$ & $2.81(2.72-2.89)$ & $3.05(2.97-3.13)^{b}$ \\
\hline *TG, mmol/L & $1.61(1.54-1.68)$ & $1.76(1.71-1.80)^{\dagger}$ & $1.55(1.37-1.73)$ & $1.47(1.39-1.55)^{\dagger}$ \\
\hline Smoking, \% ( $n)$ & $48.2(592)$ & $0.5(15)^{b}$ & $30.1(86)$ & $0.4(2)^{\mathrm{b}}$ \\
\hline Alcohol use, \% (n) & $51.3(630)$ & $3.3(79)^{b}$ & $32.5(93)$ & $1.85(10)^{b}$ \\
\hline $\mathrm{DM}, \%(n)$ & $7.2(88)$ & $8.4(201)$ & $4.2(12)$ & $5.9(32)$ \\
\hline MS, \% (n) & $21.4(262)$ & $39.7(953)^{b}$ & $10.1(29)$ & $19.3(104)^{b}$ \\
\hline Obesity, \% (n) & $8.6(105)$ & $15.7(378)^{\mathrm{b}}$ & $3.8(11)$ & $8.5(46)^{b}$ \\
\hline $\mathrm{OHT}, \%(n)$ & $16.5(203)$ & $15.3(367)$ & $8.0(23)$ & $9.1(49)$ \\
\hline $\mathrm{OH}, \%(n)$ & $22.5(276)$ & $23.8(573)$ & $14.3(41)$ & $15.9(86)$ \\
\hline$\Delta \mathrm{SBP}$ at $0, \mathrm{mmHg}$ & $-3.1(-3.8-2.3)$ & $-3.9(-4.4--3.3)$ & $-2.87(-4.2--1.5)$ & $-3.67(-4.7--2.7)$ \\
\hline$\triangle \mathrm{DBP}$ at $0, \mathrm{mmHg}$ & $1.7(1.2-2.2)$ & $1.3(0.9-1.6)$ & $0.68(-0.32--1.68)$ & $-0.14(-0.94-0.64)$ \\
\hline$\Delta \mathrm{SBP}$ at $2 \mathrm{~min}, \mathrm{mmHg}$ & $-2.0(-2.7-1.2)$ & $-2.1(-2.7--1.6)$ & $-2.68(-4.03--1.2)$ & $-2.86(-3.8--1.8)$ \\
\hline$\triangle \mathrm{DBP}$ at $2 \mathrm{~min}, \mathrm{mmHg}$ & $3.4(2.8-3.9)$ & $2.6(2.2-2.9)^{b}$ & $1.84(0.83-2.81)$ & $0.97(0.15-1.79)$ \\
\hline
\end{tabular}

BMI indicates body mass index; SBP, systolic blood pressure; DBP, diastolic blood pressure; PP, pulse pressure; HR, heart rates; FBG, fast blood glucose; SUA, serum uric acid; SCr, serum creatinine; TC, total cholesterol; HDL-C, high density lipoprotein cholesterol; LDL-C, low density lipoprotein cholesterol; TG, triglycerides; DM, diabetes mellitus; MS, metabolic syndrome; OHT, orthostatic hypertension; OH, orthostatic hypotension; ONT, orthostatic normotension; $\triangle \mathrm{SBP}$, orthostatic change in systolic blood pressure; $\triangle \mathrm{DBP}$, orthostatic change in diastolic blood pressure. ${ }^{\dagger} P$ value analyzed by MannWhitney nonparametric test. *, values are expressed as median with $95 \%$ confidence interval. ${ }^{\mathrm{b}} P<0.05$.

associations were found between orthostatic changes in SBP or DBP at 0 or 2 min after standing and ACE or ACE2 genotypes in either men or women. Analysis of the general linear model also demonstrated no significant influence of genotype on orthostatic BP changes after controlling for confounders in both sexes. Normotensive subjects also showed no association of orthostatic BP changes with the studied genotypes (Table S1).

\section{Discussion}

This study assessed the influence of RAS genetic variants on orthostatic BP dysregulation in a large cohort of untreated hypertensive and normotensive subjects. Because RAS has been implicated in the pathophysiological mechanisms of hypertension and orthostatic BP dysregulation, $A C E$ and/or $A C E 2$ polymorphisms were hypothesized to have a genetic influence on BP response to posture change. After exclusion of the effect of antihypertensive drugs, the present study failed to demonstrate an association of either ACE or ACE2 genetic polymorphisms with $\mathrm{OHT}, \mathrm{OH}$, or orthostatic $\mathrm{BP}$ changes in either untreated hypertensive patients or normotensive sub- jects.

The prevalence of $\mathrm{OHT}$ and $\mathrm{OH}$ was similar between male and female patients in our study. Few studies have reported a gender difference in the BP response to standing ${ }^{[26,27]}$; our study and a previous large community-based study showed no significant sex-related difference in $\mathrm{BP}$ in response to postural change ${ }^{[6]}$. The small BP difference $(0.7 \mathrm{mmHg})$ between sexes in DBP at 2 min after adopting an upright position is probably not clinically relevant in hypertensive patients, even though it was statistically significant, and may be due to the large sample size. Because large fluctuations in heart rate and blood pressure usually occur within the first 20 to $30 \mathrm{~s}$ after standing ${ }^{[28]}$, the mean reduction in SBP immediately (at $0 \mathrm{~min}$ ) after standing was larger than that after $2 \mathrm{~min}$ in the upright position.

In addition to aging, the orthostatic BP response might be strongly influenced by high BP levels as well as subsequent damage to vessels and autonomic tone in hypertensive patients. Hypertension blunts baroreflex sensitivity (BRS) and vascular compliance ${ }^{[29,30]}$, and therefore may lead to the occurrence of $\mathrm{OH}$. In contrast, OHT may be related to the 
Table 2. Prevalence of $\mathrm{OHT}$ and $\mathrm{OH}$ among genotypes in hypertensive patients.

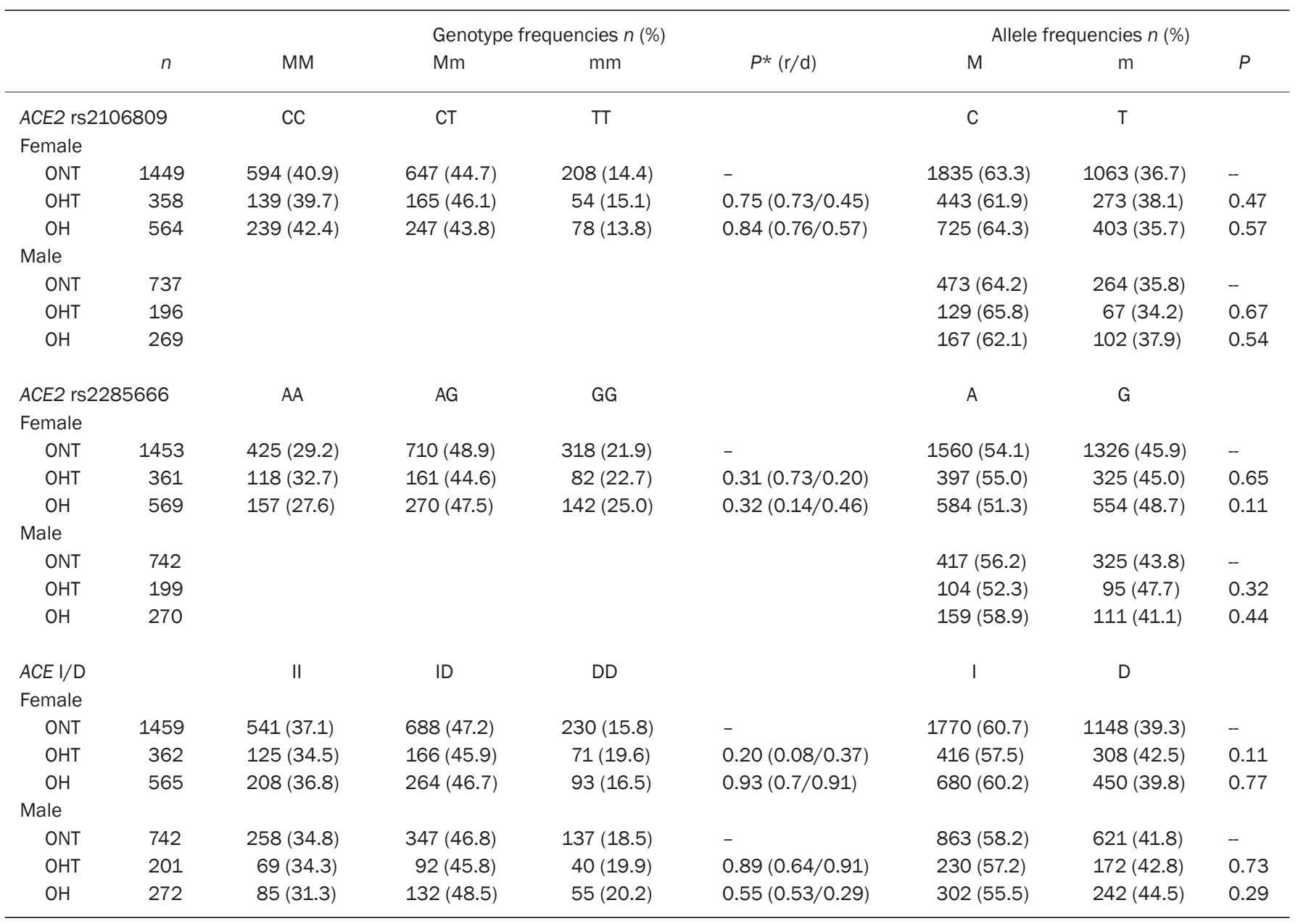

OHT indicates orthostatic hypertension; $\mathrm{OH}$, orthostatic hypotension; ONT, orthostatic normotension; M, major allele, m, minor allele, of each polymorphism. $X^{2}$ test vs ONT group; * indicates $P$ values under additive model; $(r / d), P$ values under recessive/dominant models.

sympathetic hyperactivity observed in some hypertensive patients $^{[31,32]}$. Excessive venous pooling in the lower extremities upon standing can lead to a decrease in cardiac output, which may result in vigorous activation of the sympathetic nervous system and excessive arteriolar vasoconstriction in hypertensives with sympathetic hyperactivity, thus causing OHT. Moreover, some patients with severe OHT may have relatively rare disorders such as baroreflex failure, mast cell activation disorder (mastocytosis), hyperadrenergic POTS, or pheochromocytoma ${ }^{[22]}$.

The genetic influence on orthostatic BP dysregulation $(\mathrm{OH}$ or OHT) remains understudied. Previous familial studies indicate that genes responsible for orthostatic SBP disorder may be on chromosome $13 \mathrm{q}$ or $18 \mathrm{q}^{[33,34]}$. However, no exact candidate genes have been identified as being responsible for orthostatic SBP regulation. The present study evaluated the genetic background of OHT using a candidate gene approach. However, a genetic influence of RAS was not found on orthostatic BP changes or the prevalence of OHT in hypertensive patients. A relationship between $\mathrm{OH}$ and mitochondrial DNA mutations was once reported in three families with idiopathic $\mathrm{OH}^{[15]}$. Orthostatic intolerance is also associated with a Gly49 polymorphism of the beta1 receptor gene ${ }^{[35]}$. Consistent with our results, Tabara et $a^{[19]}$ reported no association between polymorphisms of genes encoding the key components of the traditional RAS pathway and $\mathrm{OH}$ in a population-based study. In contrast, they reported an association of $\mathrm{OH}$ with a G protein a-subunit (GNAS1) T131C polymorphism and a G protein $\beta$ subunit (GNB3) C825T polymorphism ${ }^{[19]}$, which are components of the sympathetic nervous system. Although a new member of RAS, ACE2, was included in our study, a genetic effect of RAS on orthostatic BP dysregulation was not detected.

In our study, RAS genetic variants did not appear to influence the BP response to orthostasis in either hypertensive or normotensive subjects. Our results can be explained by the role of the RAS in the physiological changes during standing. The most important mechanism to compensate for short-term orthostatic stress is the influence of the autonomic nervous system on peripheral vascular resistance, heart rate and con- 
Table 3. Prevalence of $\mathrm{OHT}$ and $\mathrm{OH}$ among genotypes in normotensive subjects.

\begin{tabular}{|c|c|c|c|c|c|c|c|c|}
\hline & \multirow[b]{2}{*}{$n$} & \multicolumn{4}{|c|}{ Genotype frequencies $n(\%)$} & \multicolumn{3}{|c|}{ Allele frequencies $n(\%)$} \\
\hline & & $\mathrm{MM}$ & $\mathrm{Mm}$ & $\mathrm{mm}$ & $P^{*}(\mathrm{r} / \mathrm{d})$ & M & $\mathrm{m}$ & $P$ \\
\hline \multicolumn{2}{|c|}{ ACE2 rs2106809 } & $\mathrm{CC}$ & $\mathrm{CT}$ & $\mathrm{TT}$ & & C & $\mathrm{T}$ & \\
\hline \multicolumn{9}{|l|}{ Female } \\
\hline ONT & 404 & $203(50.2)$ & $158(39.1)$ & $43(10.6)$ & - & $564(69.8)$ & $244(30.2)$ & \\
\hline OHT & 46 & $21(45.7)$ & $19(41.3)$ & $6(13.0)$ & $0.80(0.62 / 0.56)$ & $61(66.3)$ & $31(33.7)$ & 0.49 \\
\hline $\mathrm{OH}$ & 79 & $43(54.4)$ & $29(36.7)$ & $7(8.9)$ & $0.77(0.63 / 0.49)$ & $115(72.8)$ & $43(27.2)$ & 0.45 \\
\hline \multicolumn{9}{|l|}{ Male } \\
\hline ONT & 214 & & & & & $138(64.5)$ & $76(35.5)$ & \\
\hline OHT & 25 & & & & & $15(60.0)$ & $10(40.0)$ & 0.66 \\
\hline $\mathrm{OH}$ & 43 & & & & & $27(62.8)$ & $16(37.2)$ & 0.83 \\
\hline ACE2 rs & 5666 & AA & $A G$ & GG & & $A$ & $G$ & \\
\hline \multicolumn{9}{|c|}{ Female } \\
\hline ONT & 406 & $111(27.3)$ & $199(49.0)$ & $96(23.6)$ & -- & $421(51.8)$ & $391(48.2)$ & \\
\hline $\mathrm{OHT}$ & 47 & $13(27.7)$ & $25(53.3)$ & 9 (19.1) & $0.77(0.49 / 0.96)$ & $51(54.3)$ & $43(45.7)$ & 0.66 \\
\hline $\mathrm{OH}$ & 81 & $26(32.1)$ & $38(46.9)$ & $17(21.0)$ & $0.67(0.61 / 0.38)$ & $90(55.6)$ & $72(44.4)$ & 0.39 \\
\hline \multicolumn{9}{|l|}{ Male } \\
\hline ONT & 215 & & & & & $119(55.3)$ & $96(44.7)$ & \\
\hline $\mathrm{OHT}$ & 25 & & & & & $13(52.0)$ & $12(48.0)$ & 0.75 \\
\hline $\mathrm{OH}$ & 44 & & & & & $25(56.8)$ & $19(43.2)$ & 0.86 \\
\hline$A C E I / D$ & & II & ID & DD & & I & D & \\
\hline \multicolumn{9}{|l|}{ Female } \\
\hline ONT & 406 & $137(33.7)$ & $189(46.6)$ & $80(19.7)$ & - & $463(57.0)$ & $349(43.0)$ & \\
\hline OHT & 47 & $16(34.0)$ & $18(38.3)$ & $13(27.7)$ & $0.38(0.23 / 0.97)$ & $50(53.2)$ & $44(46.8)$ & 0.48 \\
\hline $\mathrm{OH}$ & 82 & $23(28.0)$ & $42(51.2)$ & $17(20.7)$ & $0.60(0.91 / 0.32)$ & $88(53.7)$ & $76(46.3)$ & 0.43 \\
\hline \multicolumn{9}{|l|}{ Male } \\
\hline ONT & 214 & $70(32.7)$ & $106(49.5)$ & $38(17.8)$ & - & $246(57.5)$ & $182(42.5)$ & \\
\hline $\mathrm{OHT}$ & 25 & $9(36.0)$ & $13(52.0)$ & $3(12.0)$ & $0.77(0.47 / 0.74)$ & $31(62.0)$ & $19(38.0)$ & 0.47 \\
\hline $\mathrm{OH}$ & 44 & $13(34.1)$ & $24(54.3)$ & $7(11.4)$ & $0.58(0.69 / 0.68)$ & $50(56.8)$ & $38(43.2)$ & 0.91 \\
\hline
\end{tabular}

$\mathrm{OHT}$ indicates orthostatic hypertension; $\mathrm{OH}$, orthostatic hypotension; ONT, orthostatic normotension; $\mathrm{M}$, major allele, m, minor allele, of each polymorphism. $X^{2}$ test vs ONT group; * indicates $P$ values under additive model; $(r / d), P$ values under recessive/dominant models.

Table 4. Orthostatic BP changes among genotypes in hypertensive patients.

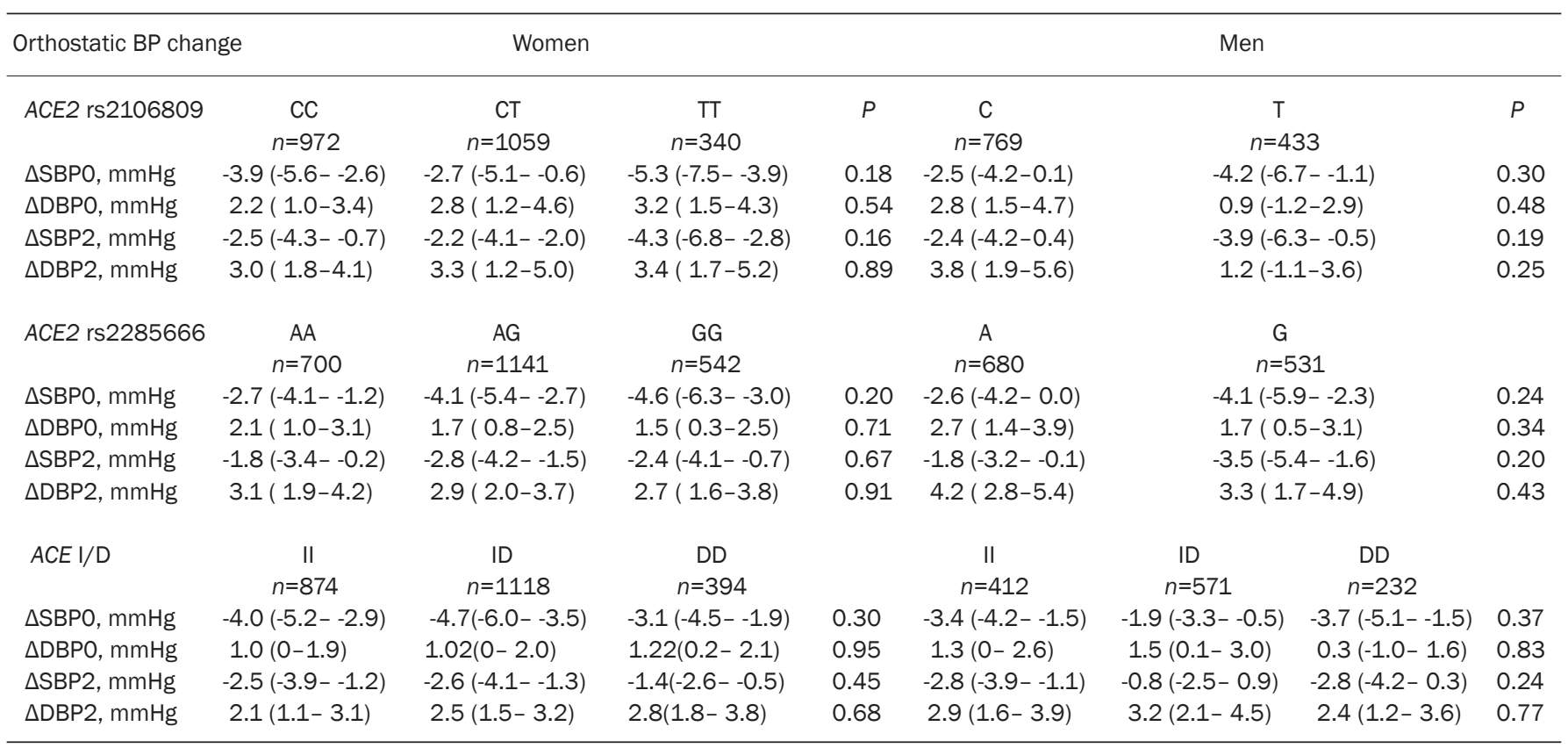


Table S1. Orthostatic BP changes among genotypes in normotensive subjects.

\begin{tabular}{|c|c|c|c|c|c|c|c|c|}
\hline \multirow{2}{*}{$\begin{array}{l}\text { Orthostatic BP change } \\
\text { ACE2 rs2106809 }\end{array}$} & \multicolumn{4}{|c|}{ Women } & \multicolumn{4}{|c|}{ Men } \\
\hline & $\mathrm{CC}$ & CT & $\mathrm{TT}$ & $P$ & C & & $P$ \\
\hline & $n=267$ & $n=206$ & $n=56$ & & $n=180$ & \multicolumn{2}{|c|}{$n=102$} & \\
\hline$\triangle \mathrm{SBPO}, \mathrm{mmHg}$ & $-3.5(-5.2--2.1)$ & $-4.3(-6.1--2.3)$ & $-4.6(-6.3--2.7)$ & 0.84 & $-2.0(-3.6-0.7)$ & \multicolumn{2}{|c|}{$-1.2(-3.1-1.4)$} & 0.80 \\
\hline$\triangle \mathrm{DBPO}, \mathrm{mmHg}$ & $0.3(-1.3-1.6)$ & $0.8(-1.4-1.9)$ & $0.6(-1.5-1.8)$ & 0.35 & $1.1(-0.9-2.3)$ & \multicolumn{2}{|c|}{$1.8(-0.6-3.2)$} & 0.71 \\
\hline$\triangle \mathrm{SBP} 2, \mathrm{mmHg}$ & $-2.4(-4.5--1.3)$ & $-3.0(-5.1--1.5)$ & $-3.2(-5.4--1.4)$ & 0.24 & $-2.6(-4.8--0.1)$ & \multicolumn{2}{|c|}{$-0.4(-2.7-3.4)$} & 0.36 \\
\hline \multirow[t]{2}{*}{ ACE2 rs2285666 } & AA & $A G$ & $\mathrm{GG}$ & & A & \multicolumn{2}{|l|}{ G } & \\
\hline & $n=150$ & $n=262$ & $n=122$ & & $n=157$ & \multicolumn{2}{|c|}{$n=127$} & \\
\hline$\triangle \mathrm{SBPO}, \mathrm{mmHg}$ & $-3.4(-5.6--1.2)$ & $-4.5(-6.6--2.3)$ & $-4.2(-6.2--2.1)$ & 0.78 & $-2.7(-4.3--0.1)$ & \multicolumn{2}{|c|}{$-3.0(-4.6--0.9)$} & 0.86 \\
\hline$\triangle \mathrm{DBPO}, \mathrm{mmHg}$ & $0.2(-1.3-1.1)$ & $0.5(-1.4-1.9)$ & $-1.1(-0.5-1.9)$ & 0.17 & $0.4(-1.5-1.9)$ & \multicolumn{2}{|c|}{$0.7(-0.6-1.7)$} & 0.87 \\
\hline$\triangle \mathrm{SBP} 2, \mathrm{mmHg}$ & $-2.8(-4.5--1.4)$ & $-3.8(-4.9--1.7)$ & $-3.4(-5.6--1.2)$ & 0.79 & $-1.7(-3.3--0.1)$ & \multicolumn{2}{|c|}{$-3.0(-4.3-0.3)$} & 0.51 \\
\hline$\triangle \mathrm{SBPO}, \mathrm{mmHg}$ & $-3.5(-5.9--1.1)$ & $-4.4(-6.1--2.2)$ & $-6.8(-8.9--3.5)$ & 0.24 & $-4.5(-6.9--2.1)$ & $-2.9(-5.1--0.3)$ & $-3.6(-5.8--0.6)$ & 0.81 \\
\hline$\triangle \mathrm{DBPO}, \mathrm{mmHg}$ & $-1.9(-3.2--0.3)$ & $-1.1(-2.5-0.1)$ & $-1.2(-3.6-0.7)$ & 0.80 & $-0.2(-1.6-1.9)$ & $0.64(-1.4-2.4)$ & $-1.1(-2.3-0.8)$ & 0.51 \\
\hline$\triangle \mathrm{SBP} 2, \mathrm{mmHg}$ & $-3.9(-6.2--1.7)$ & $-3.6(-5.1--1.8)$ & $-4.2(-7.8--2.9)$ & 0.94 & $-3.9(-6.1--1.3)$ & $-1.7(-3.5-0.3)$ & $-5.2(-7.1--2.9)$ & 0.24 \\
\hline$\triangle \mathrm{DBP} 2, \mathrm{mmHg}$ & $-1.2(-2.9-0.1)$ & $0.2(-1.3-1.8)$ & $-0.2(-2.1-1.3)$ & 0.59 & $1.6(-0.5-2.8)$ & $2.2(0.9-3.8)$ & $-0.7(-2.5-1.6)$ & 0.26 \\
\hline
\end{tabular}

$\triangle \mathrm{SBPO}$ indicates systolic blood pressure changes at 0 min after standing; $\triangle \mathrm{SBP} 2$, systolic blood pressure changes at 2 min after standing; $\triangle \mathrm{DBPO}$ or 2 , diastolic blood pressure changes at 0 or 2 min after standing. Data are expressed as mean $(95 \% \mathrm{Cl}$ of differences).

tractility, and muscular activity. Continued upright posture causes greater volume depletion, and this activates a series of neurohormonal changes, including activation of the RAS. OH and OHT are commonly recognized within 3 min upon standing, which may be independent of the RAS effect. Another possibility is that the underlying causal variants of RAS were not detected by appropriate analysis. However, this explanation is not supported by the consistency of our results with previous studies or the physiological role of RAS in orthostasis. To further understand the genetic background of orthostatic $\mathrm{BP}$ regulation, more studies are required to assess genetic effects of the sympathetic nervous system on orthostatic BP response.

Several limitations need to be mentioned. Because the study sample size was large enough to entail a low probability of a false-negative result, we did not replicate our results in another independent sample of hypertensive patients. In addition, the similar results in normotensive subjects also verified the reliability of our findings. Although haplotype analyses including all variants can often have advantages over polymorphism analyses, tag-SNPs based on LD analysis can also provide potential power and good coverage of the total common variation ${ }^{[36]}$. Nevertheless, it might be necessary to investigate all polymorphisms in all genes encoding pathways of both the sympathetic nervous system and RAS to further evaluate genetic background of orthostatic BP dysregulation.

In conclusion, our results provide no evidence for either $A C E$ or ACE2 involvement in the genetic predisposition for orthostatic BP dysregulation in hypertensive patients or nor- motensive subjects. The data presented should be helpful for elucidating the genetic mechanisms underlying orthostatic hypotension and hypertension in future studies.

\section{Acknowledgments}

This work was supported by National Natural Science Foundation of China with grant 30871054 to Dr Xiao-han FAN and the National High Technology Research and Development Program of China (863 Program) with grant 2006AA02Z477 to Dr Ru-tai HUI. We appreciate the cooperation of the patients and the many investigators in FuWai, Beijing center and local clinical centers in XinYang, He-nan province.

\section{Author contribution}

Ru-tai HUI and Xiao-han FAN designed research; Xiao-han FAN, Yi-bo WANG, Hu WANG, Xiao-dong SONG, Jing-zhou CHENG, Hai-ying WU, and Xiang-liang ZHOU performed research; Kai SUN and Wei-li ZHANG contributed new analytical tools and reagents; Xiao-han FAN and Kai SUN analyzed data; Xiao-han FAN and Ru-tai HUI wrote the paper.

\section{Supplementary file}

This is a table for associations of orthostatic blood pressure (BP) changes with studied genotypes in normotensive subjects. The orthostatic BP changes were comparable among all studied genotypes of the ACE and ACE2 genes.

\section{References}

1 Masaki KH, Schatz IJ, Burchfiel CM, Sharp DS, Chiu D, Foley D, et 
al. Orthostatic hypotension predicts mortality in elderly men: the Honolulu Heart Program. Circulation 1998; 98: 2290-5.

2 Eigenbrodt ML, Rose KM, Couper DJ, Arnett DK, Smith R, Jones D. Orthostatic hypotension as a risk factor for stroke: the Atherosclerosis Risk In Communities (ARIC) study, 1987-1996. Stroke 2000; 31: 2307-13.

3 Rose KM, Tyroler HA, Nardo CJ, Arnett DK, Light KC, Rosamond W, et al. Orthostatic hypotension and the incidence of coronary heart disease: the Atherosclerosis Risk in Communities study. Am J Hypertens 2000;13: 571-8.

4 Luukinen H, Koski K, Laippala P, Airaksinen KE. Orthostatic hypotension and the risk of myocardial infarction in the home-dwelling elderly. J Intern Med 2004; 255: 486-93.

5 Rose KM, Eigenbrodt ML, Biga RL, Couper DJ, Light KC, Sharrett AR, et al. Orthostatic hypotension predicts mortality in middle-aged adults: the Atherosclerosis Risk in Communities (ARIC) study. Circulation 2006; 114: 630-6.

6 Nardo CJ, Chambless LE, Light KC, Rosamond WD, Sharrett AR, Tell GS, et al. Descriptive epidemiology of blood pressure response to change in body position: The ARIC study. Hypertension 1999; 33: 1123-9.

7 Kario K, Eguchi K, Hoshide S, Hoshide Y, Umeda Y, Mitsuhashi T, et al. U-curve relationship between orthostatic blood pressure change and silent cerebrovascular disease in elderly hypertensives: orthostatic hypertension as a new cardiovascular risk factor. J Am Coll Cardiol 2002; 40: 133-41.

8 Matsubayashi K, Okumiya K, Wada T, Osaki Y, Fujisawa M, Doi Y, et al. Postural dysregulation in systolic blood pressure is associated with worsened scoring on neurobehavioral function tests and leukoaraiosis in the older elderly living in a community. Stroke 1997; 28: 2169-73.

9 Shin C, Abbott RD, Lee H, Kim J, Kimm K. Prevalence and correlates of orthostatic hypotension in middle-aged men and women in Korea: the Korean Health and Genome Study. J Hum Hypertens 2004; 18 : 717-23.

10 Ray CA, Monahan KD. Aging attenuates the vestibulosympathetic reflex in humans. Circulation 2002; 105: 956-61.

11 Kario K, Eguchi K, Nakagawa Y, Motai K, Shimada K. Relationship between extreme dippers and orthostatic hypertension in elderly hypertensive patients. Hypertension 1998; 31: 77-82.

12 Grubb, BP. Neurocardiogenic syncope and related disorders of orthostatic intolerance. Circulation 2005; 111: 2997-3006.

13 Harrap SB, Cui JS, Wong ZY, Hopper JL. Familial and genomic analyses of postural changes in systolic and diastolic blood pressure. Hypertension 2004; 43: 586-91.

14 Shannon JR, Flattem NL, Jordan J, Jacob G, Black BK, Biaggioni I, et al. Orthostatic intolerance and tachycardia associated with norepinephrinetransporter deficiency. N Engl J Med 2000; 342: 541-9.

15 Schwartz F, Baldwin CT, Baima J, Gavras H. Mitochondrial DNA mutations in patients with orthostatic hypotension. Am J Med Genet 1999; 86: 145-50.

16 Tipnis SR, Hooper NM, Hyde R, Karran E, Christie G, Turner AJ. A human homolog of angiotensin-converting enzyme. Cloning and functional expression as a captopril-insensitive carboxypeptidase. J Biol Chem 2000; 275: 33238-43.

17 Donoghue M, Hsieh F, Baronas E, Godbout K, Gosselin M, Stagliano $\mathrm{N}$, et al. A novel angiotensin-converting enzyme-related carboxypeptidase (ACE2) converts angiotensin I to angiotensin 1-9. Circ Res 2000; 87: E1-9.

18 Yagil Y, Yagil C. Hypothesis: ACE2 modulates blood pressure in the mammalian organism. Hypertension 2003; 41: 871-3.

19 Tabara Y, Kohara K, Miki T. Polymorphisms of genes encoding components of the sympathetic nervous system but not the reninangiotensin system as risk factors for orthostatic hypotension. J Hypertens 2002; 20: 651-6.

20 Perloff D, Grim C, Flack J, Frohlich ED, Hill M, McDonald M. Human blood pressure determination by sphygmomanometry. Circulation 1993; 88: $2460-70$.

21 The Consensus Committee of the American Autonomic Society and the American Academy of Neurology. Consensus statement on the definition of orthostatic hypotension, pure autonomic failure, and multiple system atrophy. Neurology 1996; 46: 1470.

22 Fessel J, Robertson D. Orthostatic hypertension: when pressor reflexes overcompensate. Nat Clin Pract Nephrol 2006; 2: 424-31.

23 Fan X, Wang Y, Sun K, Zhang W, Yang X, Wang S, et al. Polymorphisms of ACE2 gene are associated with essential hypertension and antihypertensive effects of Captopril in women. Clin Pharmacol Ther 2007; 82: 187-96.

24 Rigat B, Hubert C, Alhenc-Gelas F, Cambien F, Corvol P, Soubrier F. An insertion/deletion polymorphism in the angiotensin I-converting enzyme gene accounting for half the variance of serum enzyme levels. J Clin Invest 1990; 86: 1343-6.

25 Hamon M, Fradin S, Denizet A, Filippi-Codaccioni E, Grollier G, Morello R. Prospective evaluation of the effect of an angiotensin I converting enzyme gene polymorphism on the long term risk of major adverse cardiac events after percutaneous coronary intervention. Heart 2003; 89: 321-5.

26 Gotshall RW, Tsai PF, Bassett Frey MA. Gender-based differences to the cardiovascular response to standing. Aviat Space Environ Med 1991; 62: 855-9.

27 Schondorf R, Low PA. Gender related differences in the cardiovascular responses to upright tilt in normal subjects. Clin Auton Res 1992; 2: 183-7.

28 Borst C, van Brederode JFM, Wieling W, van Montfrans GA, Dunning AJ. Mechanisms of initial blood pressure response to postural change. Clin Sci 1984; 67: 321-7.

29 Lye M, Vargas E, Faragher EB, Davies I, Goddard C. Haemodynamic and neurohumoral responses in elderly patients with postural hypotension. Eur J Clin Invest 1990; 20: 90-6.

30 Harrington F, Murray A, Ford GA. Relationship of baroreflex sensitivity and blood pressure in an older population. J Hypertens 2000; 18 : 1629-33.

31 Matsukawa T, Mano T, Gotoh E, Ishii M. Elevated sympathetic nerve activity in patients with accelerated essential hypertension. J Clin Invest 1993; 92: 25-8.

32 Grassi G, Seravalle G, Bertinieri G, Turri C, Dell'Oro R, Stella ML. Sympathetic and reflex alterations in systo-diastolic and systolic hypertension of the elderly. J Hypertens 2000; 18: 587-93.

33 Pankow JS, Rose KM, Oberman A, Hunt SC, Atwood LD, Djousse L, et al. Possible locus on chromosome $18 q$ influencing postural systolic blood pressure changes. Hypertension 2000; 36: 471-6.

34 North KE, Rose KM, Borecki IB, Oberman A, Hunt SC, Miller MB, et al. Evidence for a gene on chromosome 13 influencing postural systolic blood pressure change and body mass index. Hypertension 2004; 43: 780-4.

35 Winker R, Barth A, Valic E, Maier R, Osterode W, Pilger A, et al. Functional adrenergic receptor polymorphisms and idiopathic orthostatic intolerance. Int Arch Occup Environ Health 2005; 78: 171-7.

36 Balding DJ. A tutorial on statistical methods for population association studies. Nat Rev Genet 2006; 7: 781-91. 